Article

\title{
Antimicrobial Porous Surfaces Prepared by Breath Figures Approach
}

\author{
Alexandra Muñoz-Bonilla ${ }^{1, *}$, Rocío Cuervo-Rodríguez ${ }^{2}$ (i) , Fátima López-Fabal $^{3}$ (1), \\ José L. Gómez-Garcés ${ }^{3}$ and Marta Fernández-García ${ }^{1, *}$ ib \\ 1 Instituto de Ciencia y Tecnología de Polímeros (ICTP-CSIC), C/Juan de la Cierva 3, 28006 Madrid, Spain \\ 2 Facultad de Ciencias Químicas, Universidad Complutense de Madrid, Avenida Complutense s/n, \\ Ciudad Universitaria, 28040 Madrid, Spain; rociocr@quim.ucm.es \\ 3 Hospital Universitario de Móstoles, C/Río Júcar, s/n, Móstoles, 28935 Madrid, Spain; \\ flopezf@salud.madrid.org (F.L.-F.); jlgarces@microb.net (J.L.G.-G.) \\ * Correspondence: sbonilla@ictp.csic.es (A.M.-B.); martafg@ictp.csic.es (M.F.-G.)
}

Received: 2 July 2018; Accepted: 20 July 2018; Published: 24 July 2018

\begin{abstract}
Herein, efficient antimicrobial porous surfaces were prepared by breath figures approach from polymer solutions containing low content of block copolymers with high positive charge density. In brief, those block copolymers, which were used as additives, are composed of a polystyrene segment and a large antimicrobial block bearing flexible side chain with 1,3-thiazolium and 1,2,3-triazolium groups, $\mathrm{PS}_{54}-b$-PTTBM- $\mathrm{M}_{44}, \mathrm{PS}_{54}-b$-PTTBM- $\mathrm{B}_{44}$, having different alkyl groups, methyl or butyl, respectively. The antimicrobial block copolymers were blended with commercial polystyrene in very low proportions, from 3 to $9 \mathrm{wt} \%$, and solubilized in THF. From these solutions, ordered porous films functionalized with antimicrobial cationic copolymers were fabricated, and the influence of alkylating agent and the amount of copolymer in the blend was investigated. Narrow pore size distribution was obtained for all the samples with pore diameters between 5 and $11 \mu \mathrm{m}$. The size of the pore decreased as the hydrophilicity of the system increased; thus, either as the content of copolymer was augmented in the blend or as the copolymers were quaternized with methyl iodide. The resulting porous polystyrene surfaces functionalized with low content of antimicrobial copolymers exhibited remarkable antibacterial efficiencies against Gram positive bacteria Staphylococcus aureus, and Candida parapsilosis fungi as microbial models.
\end{abstract}

Keywords: antimicrobial coatings; porous surfaces; breath figures

\section{Introduction}

Healthcare-associated infections are a major problem nowadays, causing high morbidity and mortality rates and substantial increase in health care costs. These infections are mainly associated with surgery procedures and medical devices such as ventilators or catheters. Prescription of antibiotics is typically used as a prevention method and/or treatment to avoid such transmissions of nosocomial pathogens; however, antibiotic consumption is a primary cause of antibiotic resistance [1], and consequently, there is an urgent need for alternatives, as well as strategies to prevent healthcare-acquired infections [2]. Inhibition of bacterial growth on the surfaces of medical equipment and devices is necessary to prevent the transmission of diseases by contact, and one promising approach is the development of antimicrobial coatings. Many of these self-disinfecting coatings are based on impregnating the surfaces with antimicrobial agents including antibiotics, silver compounds, light active species, and antimicrobial polymers such as polycations [3-7]. Other strategies limit the bacterial colonization of surfaces by inducing micro and nano-roughness, which modifies the surface area of contact with the microorganisms [8-10]. Although in the past the effect of surface topography 
on bacterial inhibition has received less attention, it is gaining popularity nowadays [11,12]. Many of these works study antifouling effects $[13,14]$ based on superhydrophobic surfaces with reduced surface contact $[10,15]$. Most of the antifouling surfaces are able to effectively reduce the initial bacterial attachment, but only within a relatively short period. If adhesion occurs, the bacteria rapidly proliferate, leading to the formation of the biofilm.

Alternatively, the introduction of roughness can produce the opposite effect, dramatically increasing the contact adhesion area. Thus, combinations of surface roughness with chemical biocidal functionalities can create more effective bactericidal properties than flat surfaces [16-18]. Nowadays, many techniques are available to create surfaces with finely controlled topography, including lithography approaches and colloidal templates $[19,20]$. Most of these techniques usually require multiple stages, expensive equipment and prefabricated masks. One of the most versatile and simple methodologies to create polymeric porous surfaces with controlled pore size, and thus tailored roughness, is the so-called breath figures approach [21-24]. This method prepares ordered porous films with water droplets as the template. Basically, polymer solution is cast onto a substrate under humid atmosphere. The solvent evaporation induces the condensation of water droplets, which self-organize into a hexagonal array and after solvent evaporation, honeycomb-patterned films are obtained. Although this technique can be used with a diversity of polymers and functionalities [25], it is limited to polymers soluble in non-polar organic solvents such as $\mathrm{CS}_{2}$ or chloroform, which are mostly hydrophobic polymers, polymers with polar end groups or some amphiphilic copolymers. An alternative for obtaining porous surfaces functionalized with highly hydrophilic polymers or polyelectrolytes is the use of polymer blends, consisting of incorporating low amount of hydrophilic polymers into a hydrophobic polymeric matrix such as polystyrene [26]. Due to the formation mechanism of the breath figures, the hydrophilic polymers tend to migrate towards the condensed water droplets, which imply their localization at the surface, on the wall of the pores [26-28]. In this context, cationic antimicrobial polymers based on quaternary ammonium groups have been incorporated into breath figures films by using blends [29]. However, only systems based on copolymers with low positive charge density have been prepared due to the difficulty to dissolve them in organic solvents $[29,30]$. In this work, we prepared porous films by a breath figures approach functionalized with high charge density by the incorporation of antimicrobial cationic polymers bearing two quaternary ammonium groups per monomeric unit. In fact, these structures are based on methacrylic monomers with 1,3-thiazolium and 1,2,3-triazolium side-chain groups, and have demonstrated a broad spectrum of antimicrobial activity in solution [31,32], and also when immobilized onto a surface $[16,33]$. It is well known that surface positive charge density is an important parameter for defining antimicrobial efficiency [33,34], and the incorporation of polymers with high charge density as blend component will enhance the biocidal activity of the microstructured surfaces, maintaining the physicochemical properties of the resulting coating.

\section{Experimental Section}

\subsection{Materials}

Film preparation: high molecular weight polystyrene (PS, Aldrich, Schnelldorf, Germany, weight-average molecular weight, $M_{\mathrm{w}}=2.50 \cdot \times 10^{5} \mathrm{~g} \mathrm{~mol}^{-1}$ ) was employed as polymeric matrix and used as received. The block copolymers polystyrene- $b$-poly(4-(1-(2-(4-methylthiazol -5-yl)ethyl)-1H-1,2,3-triazol-4-yl)butyl methacrylate) $\left(M_{\mathrm{n}}=22,000 \mathrm{~g} / \mathrm{mol}, M_{\mathrm{w}} / M_{\mathrm{n}}=1.53\right)$ quaternized with either butyl iodide ( PS $_{54}-b$-PTTBM-B 44 ) or methyl iodide $\left(\mathrm{PS}_{54}-b\right.$-PTTBM-M 44 ) were synthesized as previously reported [16]. Briefly, the first block of polystyrene was prepared by atom transfer radical polymerization (ATRP) and then was used as macroinitiator for the synthesis of the PTTBM block. This second block was obtained by combination of ATRP and copper-catalyzed azide-alkyne cycloaddition (CuAAC) click reaction, using the same catalyst (CuCl/PMDETA). The TTBM monomer was synthesized in situ during its ATRP polymerization by click chemistry 
between 2-(4-methylthiazol-5-yl)ethanol azide and hex-5-yn-1-yl methacrylate. The cationic copolymers $\mathrm{PS}_{54}-b$-PTTBM- $\mathrm{R}_{44}(\mathrm{R}=$ butyl or methyl) were finally obtained by quaternization of their thiazole and triazole groups. ${ }^{1} \mathrm{H}-\mathrm{NMR}$ spectroscopy confirms that quaternization was achieved quantitatively [16]. Tetrahydrofuran (THF, Aldrich, St Quentin Fallavier, France, ACS reagent) was employed as organic solvent for the preparation of the porous films without further purification. Round glass coverslips of $12 \mathrm{~mm}$ diameter were obtained from Ted Pella Inc (Redding, CA, USA).

Microbiological assays: Sodium chloride $(\mathrm{NaCl}, 0.9 \%$, BioXtra, St Quentin Fallavier, France, suitable for cell cultures) and phosphate-buffered saline (PBS, pH 7.4) were obtained from Aldrich. Sheep blood (5\%) Columbia Agar plates were purchased from bioMérieux (Madrid, Spain). American Type Culture Collection (ATCC): Gram-positive Staphylococcus aureus (S. aureus, ATCC 29213) bacteria and Candida parapsilosis (C. parapsilosis, ATCC 22019) fungi were obtained from Oxoid ${ }^{\mathrm{TM}}$ (Madrid, Spain).

\subsection{Antimicrobial Film Formation}

Porous films with antimicrobial activity were fabricated by a breath figures approach. For this purpose, blends of polymers composed of commercial PS as the main component, and cationic copolymers PS $_{54}-b$-PTTBM- $\mathrm{R}_{44}\left(\mathrm{PS}_{54}-b-\mathrm{PTTBM}_{44}\right.$ or $\mathrm{PS}_{54}-b$-PTTBM- $\left.\mathrm{M}_{44}\right)$ as minor components were prepared at different compositions: 3,6 and $9 \mathrm{wt} \%$ of copolymer. The polymer mixtures were dissolved in THF at a concentration of $30 \mathrm{mg} \mathrm{mL}^{-1}$. THF was selected as organic solvent because is compatible with all the components. Then, polymer films of $1 \mathrm{~cm}$ diameter were obtained by drop casting of $30 \mu \mathrm{L}$ of each solution onto glass substrate at room temperature in a closed chamber under controlled humidity. The humidity conditions of the chamber were set to 60,70 and $90 \%$ for each solution.

\subsection{Film Characterization}

The surface structures of the films were observed by a scanning electron microscope (Philips XL30, Eindhoven, The Netherlands) with an acceleration voltage of $25 \mathrm{kV}$. The films were coated with gold-palladium $(80 / 20)$ prior to imaging. The pore diameters and the quantitative order of porous patterns were analyzed by the image analysis software Image-J (NIHimage, National Institutes of Health, Bethesda, MD, USA). Water contact angle measurements of the prepared films were carried out in a KSV Theta goniometer (KSV Instruments Ltd., Helsinki, Finland) from digital images of $3.0 \mu \mathrm{L}$ water droplets on the surface. The measurements were made in at least quintuplicate.

\subsection{Evaluation of Antimicrobial Activity in Films}

Antimicrobial activities of the prepared films were evaluated following the E2149-01 standard method from the American Society for Testing and Materials (ASTM) [35], which is a quantitative and standardized method, typically used for the analysis of material surfaces in antimicrobial materials. Firstly, the microorganisms S. aureus and C. parapsilosis were incubated on $5 \%$ sheep blood Columbia agar plates for $24 \mathrm{~h}$ for bacteria and $48 \mathrm{~h}$ for yeast at $37^{\circ} \mathrm{C}$ in a Jouan IQ050 incubator (Winchester, VA, USA). Subsequently, the microorganism concentration was adjusted with saline solution to a turbidity equivalent to ca. 0.5 McFarland turbidity standard, about $10^{8}$ colony-forming units (CFU) $\mathrm{mL}^{-1}$. The optical density of the microorganism suspensions was measured in a DensiCHEKTM Plus (VITEK, bioMérieux, Madrid, Spain). Then, these suspensions were further diluted (1:200) with PBS to obtain $10^{6} \mathrm{CFU} \mathrm{mL}{ }^{-1}$. Each film was introduced in a sterile falcon tube containing $1 \mathrm{~mL}$ of the tested inoculum and $9 \mathrm{~mL}$ of PBS to reach a working solution of ca. $10^{5} \mathrm{CFU} \mathrm{mL}{ }^{-1}$. Control experiments were also carried out on films made exclusively with commercial PS, and also blank experiments with only the tested inoculum in the absence of films. The suspensions were shaken for $24 \mathrm{~h}$ at $120 \mathrm{rpm}$. After this period, $1 \mathrm{~mL}$ of each solution was taken and serially diluted. The dilutions, $1 \mathrm{~mL}$, were placed on $5 \%$ sheep blood Columbia agar plates and incubated for $24 \mathrm{~h}$ for bacteria and $48 \mathrm{~h}$ for fungi at $37^{\circ} \mathrm{C}$. Then, the number of bacteria in each sample was determined by the plate counting method [36]. The measurements were made at least in triplicate. 


\section{Results and Discussion}

Porous films were prepared by the breath figures method from blends containing antimicrobial copolymers with high charge density as a minor component or additive. By this approach, bactericidal films on contact with antimicrobial chemical functionalities at the surface and controlled microstructure can be fabricated in a very simple and effective way. In addition, structural parameters, such as pore size and pore density, can be easily controlled by selecting the experimental conditions of humidity, concentration of the solution or the type of polymer [22]. In fact, the use of polymeric structures with polar moieties, i.e., amphiphilic polymers, favors the formation of ordered porous arrays, because these structures help the stabilization of the condensed water droplets. Herein, amphiphilic copolymers based on a hydrophilic block with two quaternary ammonium moieties per monomeric unit (Figure 1) were added to commercial polystyrene as a modifier and antimicrobial component. THF solutions of these blends were cast onto glass substrates under controlled humidity. It has to be mentioned that the cationic copolymers $\mathrm{PS}_{54}-b-\mathrm{PTTBM}-\mathrm{R}_{44}$ are not soluble in the common organic solvents typically used in the breath figures approach, such as $\mathrm{CS}_{2}$ and chloroform. Thus, THF was selected to be more compatible with both components of the blend, although it is known that THF is not an ideal solvent and typically leads to irregular arrays due to its miscibility with water. Nevertheless, THF only allows the solubility of low content of copolymers. For this reason, THF solution was prepared with a polymeric concentration of $30 \mathrm{mg} / \mathrm{mL}$, with PS/PS ${ }_{54}-b-\mathrm{PTTBM}^{\mathrm{R}} \mathrm{R}_{44}$ ratios of $97 / 3,94 / 6$ and $91 / 9 \mathrm{wt} \%$.

Films were prepared from these THF solutions under different humidities: $60 \%, 70 \%$ and $90 \%$. As mentioned above, the relative humidity is a fundamental parameter in the preparation of porous films by the breath figures approach and has a large impact on the morphology of the films. As shown in Figure 1, when the humidity was set at $60 \%$, only flat surfaces were obtained; thus, in this case, higher humidity was necessary to fabricate porous films. In effect, at higher humidity values, such as $70 \%$ and $90 \%$, porous films were found; however, films prepared at $90 \%$ show irregular patterns containing large and heterogeneous pores mixed with smaller pores, resulting from the coagulation of the rapidly condensing water droplets during the breath figure process, which leads to a dramatic increase in the droplet size (Figure 1c,d) [37]. On the other hand, when the humidity was set at $70 \%$, more homogeneous patterns were obtained, as shown in Figure 1b. Thus, the following experiments for the fabrication of antimicrobial surfaces were carried out under this relative humidity.

Films were prepared at $70 \%$ relative humidity from blend solutions composed of commercial PS and a low amount of the antimicrobial copolymer quaternized with butyl or methyl iodide, $\mathrm{PS}_{54}-b$-PTTBM-B 44 or $\mathrm{PS}_{54}-b$-PTTBM-M 44 , respectively. It is well known that the alkylating agents affect the efficacy of the antimicrobial polymers based on quaternary ammonium groups, because they modify the hydrophobic/hydrophilic balance [31,38]. Additionally, the alkylating agents would also influence the microstructure of the breath figure films. Figure 2 shows SEM images of the films containing different contents of copolymer prepared at $70 \%$ humidity, in which porous films are observed in all cases. Additionally, it is observed from the cross-section image that there is only a single layer with pores. In these SEM images, the influence of the type of copolymer and its concentration on the pore structure and morphology of the porous breath figure films can also be seen.

Previous works indicate that, in general, copolymers with large hydrophilic blocks produce poorly ordered structures because the interfacial tension tends to decrease and, consequently, the coalescence of the water droplets increases $[29,37,39]$. However, in this case, relatively ordered porous arrays are obtained for all the blends, using both types of antimicrobial copolymers with large cationic segments as additives. Table 1 shows the quantitative evaluation of the order obtained by using Voronoi polygon construction on low-magnification SEM images. The images were processed and analyzed by the software ImageJ to calculate the conformational entropy, which is compared with the entropy for an ideal hexagonal array $(S=0)$ and a randomly organized array $(S=1.71)$ [40]. The large entropies obtained between 1.17 and 0.86 indicate relatively poorly ordered arrays, although these values are also substantially less than $S=1.71$ for random packaging. It has to be mentioned that they are typical values for breath figures made from water-miscible solvent such as THF [41-43]. Concerning the 
pore size, highly homogeneous pore diameters can clearly be seen for all the samples in SEM images. When the different films are compared, in general, higher diameters are obtained in films containing the copolymer quaternized with butyl, $\mathrm{PS}_{54}-b-\mathrm{PTTBM}_{44}$ (Figure $2 \mathrm{a}-\mathrm{c}$ ), which is more hydrophobic than PS $_{54}-b$-PTTBM-M 44 quaternized with methyl groups. Nevertheless, the differences are slight, as seen in Table 1, which summarizes the mean pore sizes of all prepared porous films, determined by measuring at least 100 pores from the SEM images. Additionally, when the concentration of both copolymers incorporated into the films is varied from 3 to $9 \mathrm{wt} \%$, a slight influence is noted in the pore size, which decreases when the content of copolymer increases.

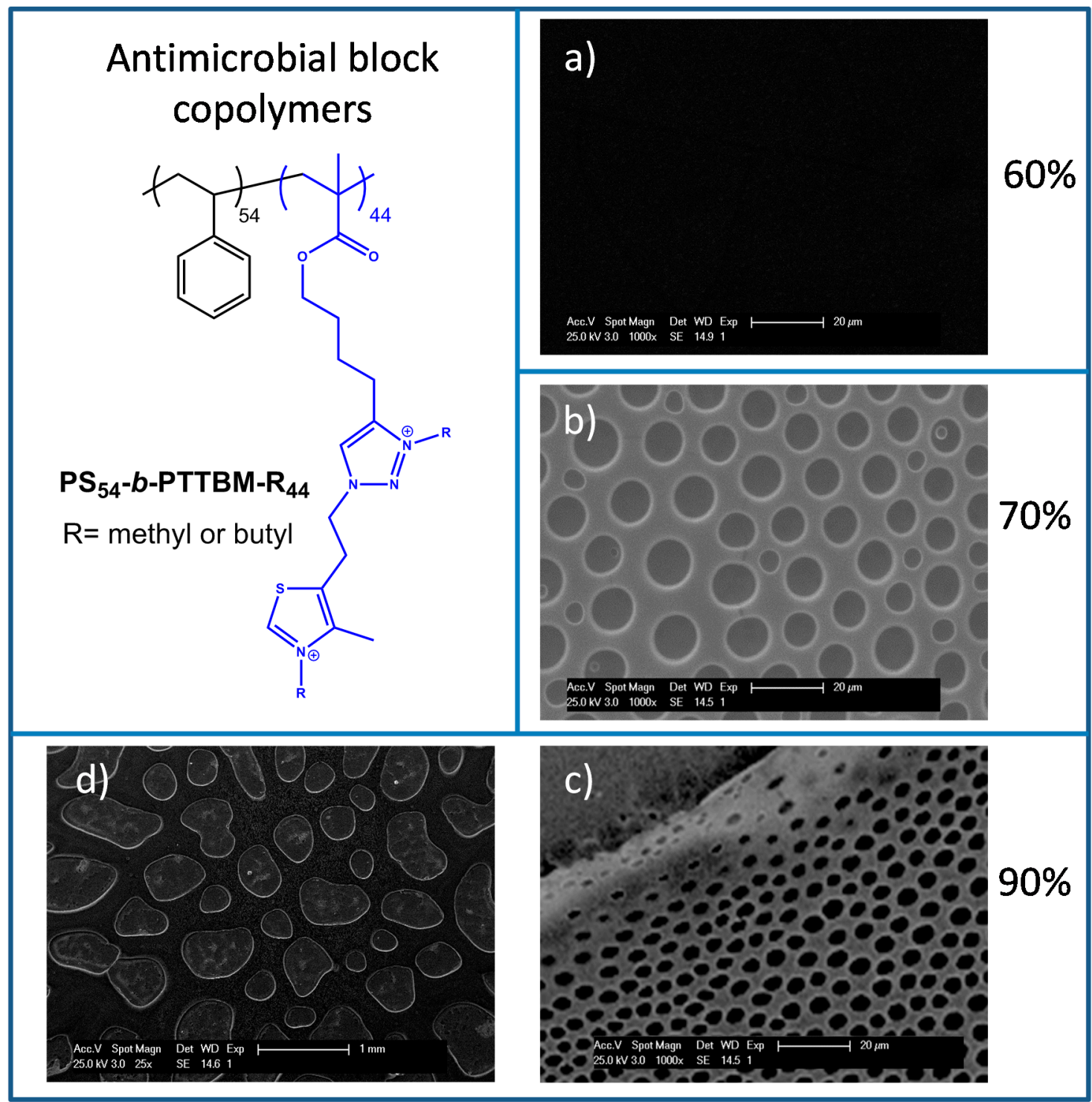

Figure 1. Chemical structure of the antimicrobial block copolymer quaternized with butyl $\left(\mathrm{PS}_{54}-b-\mathrm{PTTBM}-\mathrm{B}_{44}\right)$ or methyl $\left(\mathrm{PS}_{54}-b-\mathrm{PTTBM}-\mathrm{M}_{44}\right)$ iodides, and SEM images of the films of PS/PS ${ }_{54}-b$-PTTBM-B 44 blends, $97 / 3$ wt $\%$ obtained from THF solutions at (a) $60 \%$; (b) $70 \%$; and (c,d) $90 \%$ relative humidity. 

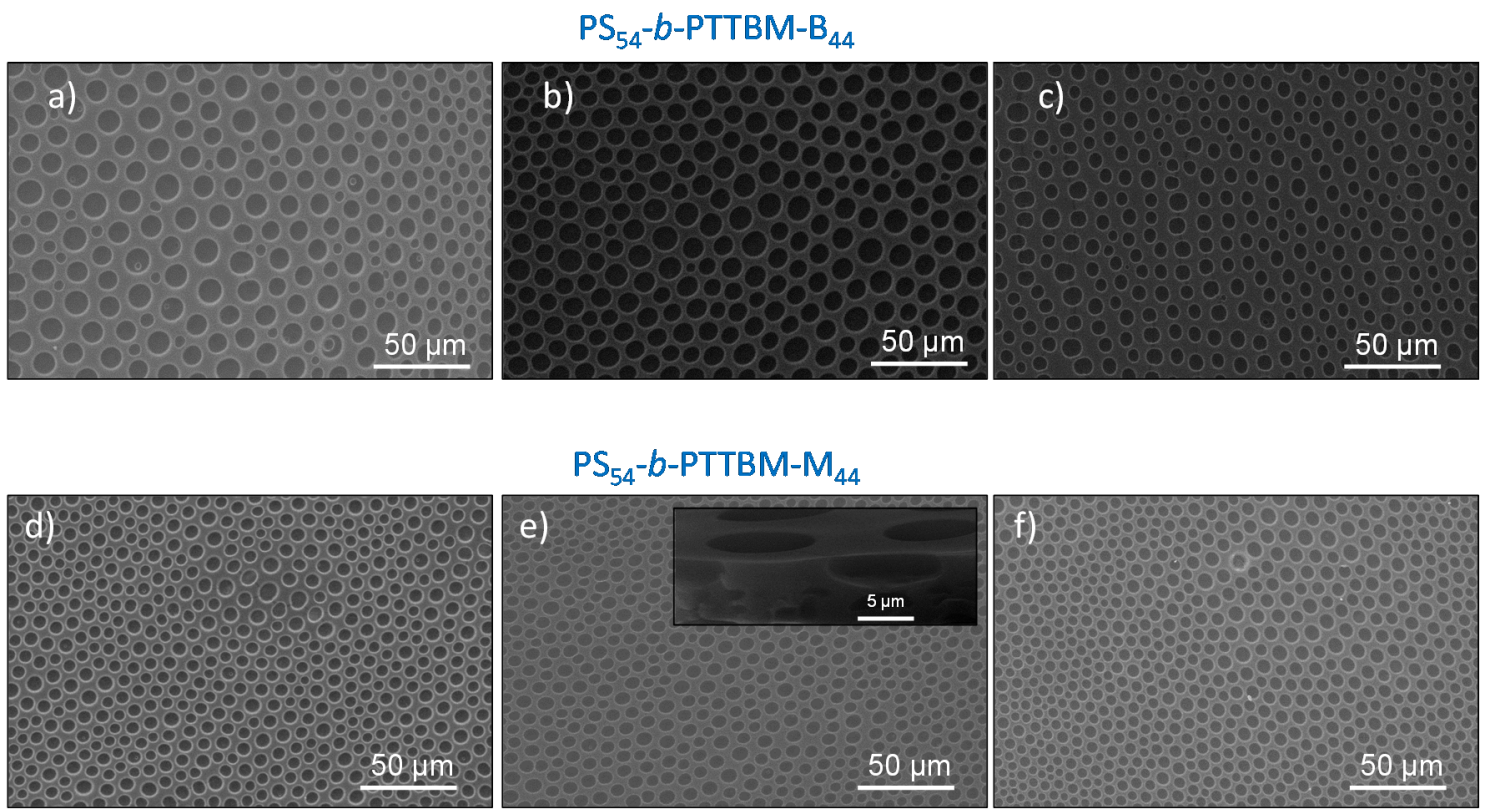

Figure 2. SEM micrographs of films obtained at $70 \%$ relative humidity composed of PS/PS 54 -b-PTTBM-B 44 blends: (a) 97/3 wt \%; (b) 94/6 wt \%; (c) 91/9 wt \%; and PS/ PS $54-b-$ PTTBM-M $_{44}$ blends: (d) $97 / 3 \mathrm{wt} \%$; (e) $94 / 6 \mathrm{wt} \%$ (inset: cross-section); (f) $91 / 9 \mathrm{wt} \%$.

Table 1. Average pore diameter $\pm \mathrm{SD}$ (standard deviation), conformational entropy $(\mathrm{S})$, and roughness factor $\left(r_{\mathrm{f}}\right)$ of porous films containing variable content of the cationic copolymers PS $_{54}-b$-PTTBM- ${ }_{44}$ and $\mathrm{PS}_{54}-b$-PTTBM-M 44 .

\begin{tabular}{ccccc}
\hline Cationic Copolymer & Concentration (wt. \%) & $\mathbf{S}$ & Pore Size $(\boldsymbol{\mu m})$ & $\mathbf{r}_{\mathbf{f}}$ \\
\hline \multirow{2}{*}{ PS $_{54}-b-\mathrm{PTTBM-B}$} & & 1.16 & $11 \pm 1$ & 1.33 \\
& 3 & 0.91 & $10 \pm 1$ & 1.42 \\
& 6 & 1.17 & $7 \pm 1$ & 1.41 \\
\hline PS $_{54}-b-$ PTTBM-M $_{44}$ & 3 & 0.86 & $7 \pm 1$ & 1.47 \\
& 6 & 0.98 & $6 \pm 2$ & 1.48 \\
& 9 & 0.94 & $5 \pm 1$ & 1.48 \\
\hline
\end{tabular}

In general, we can conclude that as the hydrophilicity of the system is augmented, either by the use of more hydrophilic copolymer or by the use of more percentage of the cationic copolymer, the size of the pores decreases. It is well known in the breath figures approach that amphiphilic structures help to stabilize the water droplets condensed at the surface of the polymeric solution; thus, in polymeric blends, the content of amphiphilic copolymers significantly influences the porous structures [22]. As the content of copolymer increases in the blend, more droplets can be stabilized and, therefore, more and smaller pores can finally be formed at the surface $[22,44]$.

The surface wettability of the films and, then, their contact with culture media mainly depends on both the chemical functionality and the roughness of the surface. The water contact angle values of obtained films were found to be $\sim 120^{\circ}$ for all the samples measured, independent of the copolymer content. However, as the cationic copolymer content increases in the sample, so does the hydrophilicity, and the contact angle should decrease. Therefore, the roughness of the sample, as expected, also contributes to the wettability of the films $[45,46]$. Table 1 summarizes the Wenzel roughness factor, $\mathrm{r}_{\mathrm{f}}$, defined as the ratio between the actual and the projected areas of the surface [47]. This factor is equal to one for flat surfaces and is greater than one for rough surfaces. It is observed that the roughness of the films increases with the content of the copolymers, and in films containing the copolymer quaternized with methyl iodide. Pore diameter slightly decreases with the content of 
the cationic copolymer, but at the same time, pore density also increases, which contributes to the augmentation of the roughness. These contrary contributions to wettability, chemical functionality and roughness could be the reason for the similar contact angles values found in the films. Therefore, in principle, microbial contact with the surface would be rather similar for all the samples.

The antimicrobial activity of the prepared breath figure films was evaluated against $S$. aureus Gram-positive bacteria and the fungi $C$. parapsilosis as model microbes, since they are common pathogens responsible of many nosocomial infections. The shake flask method [36] was employed to quantify the antimicrobial activity of the films under dynamic contact conditions. Table 2 summarizes the cell killing percentage in microbial medium in contact with the films for $24 \mathrm{~h}$, and then the growth in agar plates for $24 \mathrm{~h}$ and $48 \mathrm{~h}$ for bacteria and fungi, respectively. The cell killing percentages were expressed with respect to control experiments in which the microbial reduction was null (experiments performed with films prepared from commercial PS, $0 \mathrm{wt} \%$ of copolymers, and without any films).

Table 2. Cell killing percentage of the breath figure films for S. aureus and C. parapsilosis microorganisms.

\begin{tabular}{cccc}
\hline \multirow{2}{*}{ Cationic Copolymer } & Concentration (wt \%) & \multicolumn{2}{c}{ Cell Killing (\%) } \\
\cline { 3 - 4 } & & S. aureus & C. parapsilosis \\
\hline \multirow{2}{*}{ PS $_{54}-b-{\mathrm{PTTBM}-\mathrm{B}_{44}}^{3}$} & 99.99 & 50 \\
& 6 & 99.99 & 90 \\
& 9 & 99.99 & 90 \\
$\mathrm{PS}_{54}-b-\mathrm{PTTBM}-\mathrm{M}_{44}$ & 3 & 99.99 & 90 \\
& 6 & 99.99 & 90 \\
& 9 & 99.99 & 90 \\
\hline
\end{tabular}

It can be seen that all films exhibit high killing efficiency against $S$. aureus bacteria, with a reduction of more than $99.99 \%$ in the culture medium. On the other hand, moderate activity was found against C. parapsilosis fungi, with reduction of up to $90 \%$ for contents of copolymer higher than $6 \%$. It is worth mentioning that these films present relatively high antimicrobial activity even with very low content of cationic copolymer; films containing only $6 \mathrm{wt} \%$ copolymers can reduce $99.99 \%$ of S. aureus and $90 \%$ of $C$. parapsilosis exposure to the films. Thus, these results reveal that the preparation method provides films with enough accessible active groups at the surfaces to kill the microorganisms by surface contact, even when low amounts of copolymer are incorporated in the film. Remarkably, these breath figure films provide better efficiencies than flat films prepared directly from the copolymer solution; that is, 100 wt $\%$ of PS $54-b$-PTTBM-B ${ }_{44}$, PS $_{54}-b-$ PTTBM-M $_{44}$ [16]. These findings demonstrate the importance of the surface roughness on the antimicrobial activity of contact-active films, which allows the use of very low amounts of antimicrobial component in the coating while maintaining excellent biocidal activity.

\section{Conclusions}

In summary, efficient antimicrobial porous coatings were fabricated by the breath figures approach from blends containing very low contents of antimicrobial polymers. Highly active amphiphilic copolymers with a large cationic block bearing a flexible side chain with 1,3-thiazolium and 1,2,3-triazolium groups were used as antimicrobial polymers with high charge density. Due to the high biocidal effectiveness of the copolymers and the controlled roughness of the porous surfaces, the resulting films exhibit high killing efficiency against the studied microorganisms. Thus, we can conclude that this breath figures approach, using only a low content of cationic polymers, allows the formation of surfaces with accessible polycationic chains for killing the microorganisms S. aureus and C. parapsilosis by surface contact.

Author Contributions: Conceptualization, A.M.-B. and M.F.-G.; Methodology, R.C.-R.; Software, A.M.-B.; Validation, A.M.-B., R.C.-R. and M.F.-G.; Formal Analysis, F.L.-F. and J.L.G.-G.; Investigation, A.M.-B.; Resources, F.L.-F. and J.L.G.-G.; Data Curation, A.M.-B., R.C.-R. and M.F.-G.; Writing-Original Draft Preparation, A.M.-B.; 
Writing-Review \& Editing, M.F.-G.; Visualization, X.X.; Supervision, A.M.-B., M.F.-G.; Project Administration, M.F.-G.; Funding Acquisition, M.F.-G.

Funding: This work was supported financially by the MINECO (Project MAT2016-78437-R), the Agencia Estatal de Investigación (AEI, Spain) and Fondo Europeo de Desarrollo Regional (FEDER, EU).

Conflicts of Interest: The authors declare no conflict of interest.

\section{References}

1. Klein, E.Y.; Van Boeckel, T.P.; Martinez, E.M.; Pant, S.; Gandra, S.; Levin, S.A.; Goossens, H.; Laxminarayan, R. Global increase and geographic convergence in antibiotic consumption between 2000 and 2015. Proc. Natl. Acad. Sci. USA 2018, 115, E3463-E3470. [CrossRef] [PubMed]

2. Sugden, R.; Kelly, R.; Davies, S. Combatting antimicrobial resistance globally. Nat. Microbiol. 2016, 1, 16187. [CrossRef] [PubMed]

3. Noimark, S.; Dunnill, C.W.; Wilson, M.; Parkin, I.P. The role of surfaces in catheter-associated infections. Chem. Soc. Rev. 2009, 38, 3435-3448. [CrossRef] [PubMed]

4. Yang, C.; Ding, X.; Ono, R.J.; Lee, H.; Hsu, L.Y.; Tong, Y.W.; Hedrick, J.; Yang, Y.Y. Brush-like polycarbonates containing dopamine, cations, and PEG providing a broad-spectrum, antibacterial, and antifouling surface via one-step coating. Adv. Mater. 2014, 26, 7346-7351. [CrossRef] [PubMed]

5. Vaterrodt, A.; Thallinger, B.; Daumann, K.; Koch, D.; Guebitz, G.M.; Ulbricht, M. Antifouling and Antibacterial Multifunctional Polyzwitterion/Enzyme Coating on Silicone Catheter Material Prepared by Electrostatic Layer-by-Layer Assembly. Langmuir 2016, 32, 1347-1359. [CrossRef] [PubMed]

6. Wang, G.; Zreiqat, H. Functional Coatings or Films for Hard-Tissue Applications. Materials 2010, 3, $3994-4050$. [CrossRef] [PubMed]

7. Alvarez-Paino, M.; Juan-Rodriguez, R.; Cuervo-Rodriguez, R.; Tejero, R.; Lopez, D.; Lopez-Fabal, F.; Gomez-Garces, J.L.; Munoz-Bonilla, A.; Fernandez-Garcia, M. Antimicrobial films obtained from latex particles functionalized with quaternized block copolymers. Colloids Surf. B Biointerfaces 2016, 140, 94-103. [CrossRef] [PubMed]

8. Manabe, K.; Nishizawa, S.; Shiratori, S. Porous surface structure fabricated by breath figures that suppresses Pseudomonas aeruginosa biofilm formation. ACS Appl. Mater. Interfaces 2013, 5, 11900-11905. [CrossRef] [PubMed]

9. Hasan, J.; Jain, S.; Padmarajan, R.; Purighalla, S.; Sambandamurthy, V.K.; Chatterjee, K. Multi-scale surface topography to minimize adherence and viability of nosocomial drug-resistant bacteria. Mater. Des. 2018, 140, 332-344. [CrossRef] [PubMed]

10. Hasan, J.; Jain, S.; Chatterjee, K. Nanoscale Topography on Black Titanium Imparts Multi-biofunctional Properties for Orthopedic Applications. Sci. Rep. 2017, 7, 41118. [CrossRef] [PubMed]

11. Hasan, J.; Chatterjee, K. Recent advances in engineering topography mediated antibacterial surfaces. Nanoscale 2015, 7, 15568-15575. [CrossRef] [PubMed]

12. Muñoz-Bonilla, A.; Fernández-García, M. The roadmap of antimicrobial polymeric materials in macromolecular nanotechnology. Eur. Polym. J. 2015, 65, 46-62. [CrossRef]

13. May, R.M.; Magin, C.M.; Mann, E.E.; Drinker, M.C.; Fraser, J.C.; Siedlecki, C.A.; Brennan, A.B.; Reddy, S.T. An engineered micropattern to reduce bacterial colonization, platelet adhesion and fibrin sheath formation for improved biocompatibility of central venous catheters. Clin. Transl. Med. 2015, 4, 9. [CrossRef] [PubMed]

14. Truong, V.K.; Webb, H.K.; Fadeeva, E.; Chichkov, B.N.; Wu, A.H.; Lamb, R.; Wang, J.Y.; Crawford, R.J.; Ivanova, E.P. Air-directed attachment of coccoid bacteria to the surface of superhydrophobic lotus-like titanium. Biofouling 2012, 28, 539-550. [CrossRef] [PubMed]

15. Ivanova, E.P.; Hasan, J.; Webb, H.K.; Gervinskas, G.; Juodkazis, S.; Truong, V.K.; Wu, A.H.; Lamb, R.N.; Baulin, V.A.; Watson, G.S.; et al. Bactericidal activity of black silicon. Nat. Commun. 2013, 4, 2838. [CrossRef] [PubMed]

16. Cuervo-Rodriguez, R.; Lopez-Fabal, F.; Gomez-Garces, J.L.; Munoz-Bonilla, A.; Fernandez-Garcia, M. Contact Active Antimicrobial Coatings Prepared by Polymer Blending. Macromol. Biosci. 2017, 17, 1700258. [CrossRef] [PubMed]

17. Su, L.; Yu, Y.; Zhao, Y.; Liang, F.; Zhang, X. Strong Antibacterial Polydopamine Coatings Prepared by a Shaking-assisted Method. Sci. Rep. 2016, 6, 24420. [CrossRef] [PubMed] 
18. Wei, T.; Yu, Q.; Zhan, W.; Chen, H. A Smart Antibacterial Surface for the On-Demand Killing and Releasing of Bacteria. Adv. Healthc. Mater. 2016, 5, 449-456. [CrossRef] [PubMed]

19. Acikgoz, C.; Hempenius, M.A.; Huskens, J.; Vancso, G.J. Polymers in conventional and alternative lithography for the fabrication of nanostructures. Eur. Polym. J. 2011, 47, 2033-2052. [CrossRef]

20. Gi-Ra Yi, G.R.; Moon, J.H.; Yang, S.M. Ordered Macroporous Particles by Colloidal Templating. Chem. Mater. 2001, 13, 2613-2618.

21. Zhang, A.; Bai, H.; Li, L. Breath Figure: A Nature-Inspired Preparation Method for Ordered Porous Films. Chem. Rev. 2015, 115, 9801-9868. [CrossRef] [PubMed]

22. Muñoz-Bonilla, A.; Fernández-García, M.; Rodríguez-Hernández, J. Towards hierarchically ordered functional porous polymeric surfaces prepared by the breath figures approach. Prog. Polym. Sci. 2014, 39, 510-554. [CrossRef]

23. Widawski, G.; Rawiso, M.; François, B. Self-organized honeycomb morphology of star-polymer polystyrene films. Nature 1994, 369, 387-389. [CrossRef]

24. Escalé, P.; Rubatat, L.; Billon, L.; Save, M. Recent advances in honeycomb-structured porous polymer films prepared via breath figures. Eur. Polym. J. 2012, 48, 1001-1025. [CrossRef]

25. Hernández-Guerrero, M.; Stenzel, M.H. Honeycomb structured polymer films via breath figures. Polym. Chem. 2012, 3, 563-577. [CrossRef]

26. de Leon, A.S.; del Campo, A.; Fernandez-Garcia, M.; Rodriguez-Hernandez, J.; Munoz-Bonilla, A. Tuning the pore composition by two simultaneous interfacial self-assembly processes: Breath figures and coffee stain. Langmuir 2014, 30, 6134-6141. [CrossRef] [PubMed]

27. Bolognesi, A.; Galeotti, F.; Giovanella, U.; Bertini, F.; Yunus, S. Nanophase separation in polystyrene-polyfluorene block copolymers thin films prepared through the breath figure procedure. Langmuir 2009, 25, 5333-5338. [CrossRef] [PubMed]

28. Böker, A.; Lin, Y.; Chiapperini, K.; Horowitz, R.; Thompson, M.; Carreon, V.; Xu, T.; Abetz, C.; Skaff, H.; Dinsmore, A.D.; et al. Hierarchical nanoparticle assemblies formed by decorating breath figures. Nat. Mater. 2004, 3, 302-306. [CrossRef] [PubMed]

29. Vargas-Alfredo, N.; Santos-Coquillat, A.; Martinez-Campos, E.; Dorronsoro, A.; Cortajarena, A.L.; Del Campo, A.; Rodriguez-Hernandez, J. Highly Efficient Antibacterial Surfaces Based on Bacterial/Cell Size Selective Microporous Supports. ACS Appl. Mater. Interfaces 2017, 9, 44270-44280. [CrossRef] [PubMed]

30. Vargas-Alfredo, N.; Dorronsoro, A.; Cortajarena, A.L.; Rodriguez-Hernandez, J. Antimicrobial 3D Porous Scaffolds Prepared by Additive Manufacturing and Breath Figures. ACS Appl Mater. Interfaces 2017, 9, 37454-37462. [CrossRef] [PubMed]

31. Tejero, R.; López, D.; López-Fabal, F.; Gómez-Garcés, J.L.; Fernández-García, M. Antimicrobial polymethacrylates based on quaternized 1,3-thiazole and 1,2,3-triazole side-chain groups. Polym. Chem. 2015, 6, 3449-3459. [CrossRef]

32. Tejero, R.; Lopez, D.; Lopez-Fabal, F.; Gomez-Garces, J.L.; Fernandez-Garcia, M. High Efficiency Antimicrobial Thiazolium and Triazolium Side-Chain Polymethacrylates Obtained by Controlled Alkylation of the Corresponding Azole Derivatives. Biomacromolecules 2015, 16, 1844-1854. [CrossRef] [PubMed]

33. Tejero, R.; Gutiérrez, B.; López, D.; López-Fabal, F.; Gómez-Garcés, J.; Muñoz-Bonilla, A.; Fernández-García, M. Tailoring Macromolecular Structure of Cationic Polymers towards Efficient Contact Active Antimicrobial Surfaces. Polymers 2018, 10, 241. [CrossRef]

34. Kaur, R.; Liu, S. Antibacterial surface design-Contact kill. Prog. Surf. Sci. 2016, 91, 136-153. [CrossRef]

35. ASTM E2149-01. Standard Test Method for Determining the Antimicrobial Activity of Immobilized Antimicrobial Agents under Dynamic Contact Conditions (Withdrawn 2010); ASTM International: West Conshohocken, PA, USA, 2001. Available online: www.astm.org (accessed on 14 April 2010).

36. Clinical and Laboratory Standards Institute. Methods for Dilution Antimicrobial Susceptibility Tests for Bacteria That Grow Aerobically, 10th ed.; CLSI Document M07-A10; Clinical and Laboratory Standards Institute: Wayne, PA, USA, 2015.

37. Wong, K.H.; Davis, T.P.; Barner-Kowollik, C.; Stenzel, M.H. Honeycomb structured porous films from amphiphilic block copolymers prepared via RAFT polymerization. Polymer 2007, 48, 4950-4965. [CrossRef]

38. Muñoz-Bonilla, A.; Fernández-García, M. Polymeric materials with antimicrobial activity. Prog. Polym. Sci. 2012, 37, 281-339. [CrossRef] 
39. Bunz, U.H.F. Breath Figures as a Dynamic Templating Method for Polymers and Nanomaterials. Adv. Mater. 2006, 18, 973-989. [CrossRef]

40. Song, L.; Sharma, V.; Park, J.O.; Srinivasarao, M. Characterization of ordered array of micropores in a polymer film. Soft Matter 2011, 7, 1890-1896. [CrossRef]

41. de Leon, A.S.; del Campo, A.; Fernandez-Garcia, M.; Rodriguez-Hernandez, J.; Munoz-Bonilla, A. Hierarchically structured multifunctional porous interfaces through water templated self-assembly of ternary systems. Langmuir 2012, 28, 9778-9787. [CrossRef] [PubMed]

42. Ferrari, E.; Fabbri, P.; Pilati, F. Solvent and substrate contributions to the formation of breath figure patterns in polystyrene films. Langmuir 2011, 27, 1874-1881. [CrossRef] [PubMed]

43. Soo Park, M.; Kon Kim, J. Breath Figure Patterns Prepared by Spin Coating in a Dry Environment. Langmuir 2004, 20, 5347-5352. [CrossRef]

44. de León, A.S.; del Campo, A.; Rodríguez-Hernández, J.; Muñoz-Bonilla, A. Switchable and pH responsive porous surfaces based on polypeptide-based block copolymers. Mater. Des. 2017, 131, 121-126. [CrossRef]

45. Yabu, H.; Takebayashi, M.; Tanaka, M.; Shimomura, M. Superhydrophobic and Lipophobic Properties of Self-Organized Honeycomb and Pincushion Structures. Langmuir 2005, 21, 3235-3237. [CrossRef] [PubMed]

46. Feng, X.J.; Jiang, L. Design and Creation of Superwetting/Antiwetting Surfaces. Adv. Mater. 2006, 18, 3063-3078. [CrossRef]

47. De León, A.S.; Campo, A.D.; Labrugère, C.; Fernández-García, M.; Muñoz-Bonilla, A.; Rodríguez-Hernández, J. Control of the chemistry outside the pores in honeycomb patterned films. Polym. Chem. 2013, 4, 4024. [CrossRef]

(C) 2018 by the authors. Licensee MDPI, Basel, Switzerland. This article is an open access article distributed under the terms and conditions of the Creative Commons Attribution (CC BY) license (http:/ / creativecommons.org/licenses/by/4.0/). 